\title{
EFEITO DOS MÉTODOS DE COCÇÃO NA COMPOSIÇÃO CENTESIMAL E COLESTEROL DO PEITO DE FRANGOS DE DIFERENTES LINHAGENS ${ }^{1}$
}

\author{
Effect of cooking methods on the chemical composition and cholesterol of the \\ breast in different chickens strains
}

\author{
Josye Oliveira e Vieira ${ }^{2}$, Maria Cristina Bressan ${ }^{3}$, Peter Bitencourt Faria ${ }^{4}$, \\ Milena Wolff Ferreira ${ }^{5}$, Sibelli Passini Barbosa Ferrão ${ }^{6}$, Xisto Rodrigues de Souza ${ }^{7}$
}

\begin{abstract}
RESUMO
No presente trabalho, objetivou-se avaliar o efeito dos métodos de cocção: cozimento em água (CA), fritura em óleo de soja (FO), assado em forno convencional (FC) e assado em microondas (MO) sobre perda de peso por cocção (PPC), composição química e colesterol em peitos de frangos das linhagens Super pesadão $(\mathrm{Sp})$, Carijó $(\mathrm{Cr})$ e Cobb $(\mathrm{Cb})$. O delineamento experimental foi inteiramente casualizado, utilizando 3 linhagens, 5 métodos de cocção e 4 repetições, totalizando 60 parcelas experimentais. A PPC mais elevada foi verificada no método MO (52,35\%), seguida pelo método FC (30,59\%), FO (22,98\%) e CA (19,99). A composição centesimal foi influenciada pelos métodos de cocção. Os peitos de frangos assados em MO apresentaram a menor umidade $(56,18 \%)$ e médias mais elevadas de proteína (40,22\%), cinzas $(1,64 \%)$ e colesterol $(63,89 \mathrm{mg} / 100 \mathrm{~g})$, quando comparados aos demais métodos, comportamento observado em todas as linhagens. Os percentuais de gordura foram maiores no método FO, $(3,23 \% ; 2,53 \%$ e $1,94 \%$, para as linhagens $\mathrm{Sp}, \mathrm{Cr}$ e $\mathrm{Cb}$, respectivamente). Peitos de frango assados em microondas mostram as perdas mais elevadas e as modificações mais severas com relação à composição química, enquanto a cocção em água é a forma de cocção que menos altera a composição centesimal de peitos de frangos.
\end{abstract}

Termos para indexação: Cocção, aves, composição química.

\begin{abstract}
The present work evaluated the effects of the cooking methods: boiling (BO), pan frying (PF), roasted in conventional oven (CO) and roasted in microwaves oven (MO) on the cooking loss, chemical composition, cholesterol in breast in different chickens strains: Heavy weight $(\mathrm{Hw})$, Carijó $(\mathrm{Cr})$ and $\mathrm{Cobb}(\mathrm{Cb})$. The completely randomized design by using 3 strains, 5 cooking methods and 4 repetitions and a total of 60 experimental parcel unit was used. The higher cooking loss most was showed in the method MO (52.35\%), followed by the method CO (30.59\%), PF (22.98\%) and BO (19.99\%). The centesimal composition was influenced by the cooking methods. The breast of chickens roasted in MO shown lowest moisture $(56.18 \%)$ and the higher protein $(40.22 \%)$, ashes $(1.64 \%)$ and cholesterol averages when compared to the other methods, the same tendency of results were observed in all strains studied. The percentages of ethereal extract were higher in the method $\mathrm{PF}(3.23 \% ; 2.53 \%$ and $1.94 \%$, for the strains $\mathrm{Hw}, \mathrm{Cr}$ and $\mathrm{Cb}$, respectively. The chicken breasts cooking in the microwaves oven showed the highest losses and the most severe modifications in relation to the chemical composition, whereas the boiling is the cooking method show to be lower changes in the chemical composition of the chicken breasts
\end{abstract}

Index terms: Cooking, chickens, chemical composition.

(Recebido para publicação em 8 de setembro de 2005 e aprovado em 11 de julho de 2006)

\section{INTRODUÇÃO}

Os consumidores atuais, preocupados com a qualidade de vida, buscam novas opções de alimentos (SOUZA, 2004), bem como informações relacionadas com a composição química dos alimentos (SIMOPOULOS, 1991). A legislação brasileira por meio da Resolução RDC $\mathrm{n}^{\circ} 40$, de 21/03/2001, estabeleceu a obrigatoriedade da rotulagem nutricional de alimentos embalados, garantindo aos consumidores a possibilidade de escolhas mais saudáveis em relação à dieta. Entretanto, para carnes, a composição fornecida na embalagem corresponde ao corte cru. Embora os consumidores saibam que a cocção em óleo (fritura) resulte em alimento com maior percentual de gordura, são desconhecidos os efeitos das diferentes formas de cocção sobre a composição nutricional.

Pesquisas que avaliaram métodos de cocção mostram que o cozimento pode alterar os valores de

\footnotetext{
'Parte da Dissertação do primeiro autor apresentada à Universidade Federal de Lavras/UFLA como parte da exigência para obtenção do título de Mestre. ${ }^{2}$ Médica Veterinária, Total Alimentos S/A, MG.

${ }^{3}$ Professora do Departamento de Ciência dos Alimentos/DCA da Universidade Federal de Lavras/UFLA - Cx. P. 3037 - $37200-000$ - Lavras, MG ${ }^{4}$ Professor do CEFET - BR 364, km 329, s/no - 78.106-000 - Cuiabá, MT.

${ }^{5}$ Aluna de pós-graduação em Zootecnia da Universidade Federal de Lavras/UFLA - Cx. P. 3037 - 37200-000 - Lavras, MG.

${ }^{6}$ Professora da Universidade Estadual do Sudoeste da Bahia/UESB - Itapetinga, BA

${ }^{7}$ Professor do CEFET - BR 364, km 329, s/no - 78.106-000 - Cuiabá, MT.
} 
umidade, proteína, gordura e cinzas dos alimentos, devido à incorporação do meio de cocção e pelas perdas de nutrientes e água (BADIANI et al., 2002; FERREIRA, 2005; GALL et al., 1983; GOKOGLU et al., 2004; ROSA, 2003; STEINER-ASIEDU et al., 1991).

Estudando diferentes métodos de cocção (assado em forno convencional, fritura por imersão e fritura em frigideira) na composição química de pescados, Mai et al. (1978) e Puwastien et al. (1999), utilizando os pescados: truta (Salvelinus namaycush), rêmora (Catastomus commersonii), bluegil (Lepomis macrochirus), tilápia (Oreochromis niloticus), bagre africano (Clarias macrocephalus) e catfish (Pangasius sutchi), descreveram que a cocção ocasionou perda de umidade nos diferentes pecados, com perdas mais elevadas nos filés fritos por imersão.

A umidade, importante para a suculência e palatabilidade da carne como alimento, é mais baixa nos pescados submetidos à cocção em forno microondas, devido à perda de peso mais elevada que ocorre nesse método. Esse comportamento foi verificado em filés de cavalinha, garoupa, caranha vermelha e pampo da Flórida (GALL et al., 1983); sardinha (GARCÍA-ARIAS et al., 2003), trutas arco-íris (GOKOGLU et al., 2004) e tilápias do Nilo (FERREIRA, 2005).

Os conteúdos de proteínas, cinzas e colesterol foram mais elevados quando comparados pescados cozidos e crus, conforme reportaram Gall et al. (1983) em filés de garoupa (Epinephelus morio), caranha vermelha (Lutjanus campechanus), pampo da Flórida (Trachinotus carolinus) e cavalinha (Scomberomorus maculatus); García-Arias et al. (2003) em filés de sardinha (Sardina pilchardus); Gokoglu et al. (2004) em filés de truta arco-íris (Oncorhynchus mykiss); e Ferreira (2005) em filés de tilápia do Nilo (Oreochromis niloticus). Os autores atribuem esse comportamento à perda de água que ocorre na cocção, levando à concentração dos nutrientes.

Os percentuais de gordura são mais elevados quando os pescados são submetidos à fritura em óleo. Isso foi reportado em filés de sardinha assados em forno convencional, fritos em óleo ou grelhados (GARCÍAARIAS et al., 2003); e, filés de truta arco-íris (GOKOGLU et al., 2004) e tilápias do Nilo (FERREIRA, 2005). Os autores explicam que esse comportamento ocorre devido à absorção do óleo utilizado na cocção.

Os trabalhos que comparam os métodos de cocção utilizaram como material experimental vários tipos de pescado. Entretanto, o uso de outros tipos de carnes são escassos.
No presente trabalho, os objetivos foram avaliar a composição centesimal e teor de colesterol da carne do peito de frangos das linhagens Carijó, Super pesadão e Cobb, submetidos a diferentes métodos de cocção.

\section{MATERIAL E MÉTODOS}

Sessenta peitos (músculos pectoralis major, pectoralis minor e pectoralis superficialis), de frangos, machos e fêmeas, pertencentes às linhagens: Gris barre plumé ou Carijó (20 peitos); Máster gris plumé ou Super pesadão (20 peitos) e Cobb (20 peitos), foram submetidos a diferentes métodos de cocção.

O abate dos frangos foi efetuado de forma convencional. Em seguida ao abate, as aves foram resfriadas em câmara fria, onde permaneceram a $5^{\circ} \mathrm{C}$ por 24 $\mathrm{h}$, quando foi realizada a desossa. Os peitos de cada unidade experimental foram embalados em sacos de polietileno, identificados e congelados a $-20^{\circ} \mathrm{C}$. Para a realização das análises laboratoriais, os cortes foram descongelados em câmara fria a $4^{\circ} \mathrm{C}$, pesados e submetidos aos métodos de cocção individualmente. Os métodos de cocção utilizados foram: a) cozimento em água (CA): os cortes foram colocados em $600 \mathrm{~mL}$ de água fria, levados ao fogo médio e cozidos por 10 minutos; b) microondas (MO): os cortes foram colocados em forma de vidro coberta com filme plástico e cozidos na potência máxima por 8 minutos; c) forno convencional a gás (FC): os cortes foram colocados em forma de alumínio, cobertos com papel alumínio e assados em temperatura média alta em forno pré-aquecido por 20 minutos; e, d) cozimento em óleo (CO): os cortes foram colocados em frigideira anti-aderente com $15 \mathrm{~mL}$ de óleo de soja e virados a cada minuto, durante 6 minutos. Após a fritura, os cortes foram colocados sobre papel absorvente para a retirada do excesso de óleo e para o resfriamento.

Os cortes foram virados na metade do tempo previsto, com exceção dos cozidos em óleo, que foram virados a cada minuto. Os peitos, após o cozimento, foram mantidos à temperatura ambiente, pesados e homogeneizados para compor a amostra.

A perda de peso por cozimento (PPC) foi determinada por meio de pesagens das amostras antes e após o cozimento. A proteína bruta foi quantificada pelo método de análise de nitrogênio Kjeldahl. A gordura foi determinada pelo método de Soxhlet, a umidade em estufa a $105^{\circ} \mathrm{C}$ até obtenção de peso constante e as cinzas em mufla a $550^{\circ} \mathrm{C}$ (AOAC, 1990). Na realização das análises de colesterol, os lipídeos foram extraídos com clorofórmio/ metanol (2:1) (FOLCH et al., 1957) e o teor de colesterol foi 
determinado colorimetricamente (BOHAC et al., 1988, citados por BRAGAGNOLO \& RODRIGUEZ-AMAYA, 1995).

O delineamento experimental foi inteiramente casualizado, em esquema fatorial 3 x 5 sendo 3 linhagens, 5 métodos de cocção e 4 repetições, totalizando 60 parcelas experimentais. O teste de médias utilizado foi o Scott-Knott, e os dados foram submetidos à análise de variância pelo programa estatístico SISVAR (FERREIRA, 2000).

\section{RESULTADOS E DISCUSSÃO}

A análise de variância mostrou influência dos fatores método de cocção $(\mathrm{P}<0,01)$ e grupo genético $(\mathrm{P}<0,05)$ para os valores médios de PPC (Tabela 1).

A linhagem Carijó apresentou o maior percentual de PPC $(33,96 \%)$ em todos os métodos de cocção, enquanto as linhagens Superpesadão e Cobb apresentaram valores semelhantes $(30,56 \%$ e $29,91 \%$, respectivamente). Essa diferença de PPC pode estar associada ao tamanho médio dos peitos, sendo que as perdas mais elevadas foram observadas em peitos de menor tamanho. Embora o peso das aves tenha sido padronizado em $2 \mathrm{~kg}$, as linhagens apresentaram diferentes níveis de desenvolvimento muscular de peitos.

Comparando os métodos de cocção, a maior PPC ocorreu no método assado em microondas (52,35\%), seguida pelo método assado em forno convencional $(30,59 \%)$. Os valores mais baixos foram encontrados no método cozido em óleo (22,98\%) e cozido em água (19,99\%). Esses resultados mostraram que peitos de frango apresentam perdas mais elevadas quando submetidos à cocção em forno microondas e perdas mais baixas quando cozidos em água. Esses resultados foram observados em todas as linhagens estudadas. Comportamento semelhante foi relatado por Badiani et al. (2002), Ferreira (2005), Gall et al. (1983) e Rosa (2003).
A maior perda nos peitos assados em microondas pode ser atribuída à uniformidade da temperatura no interior e na superfície dos cortes, ao contrário do que ocorre nos outros métodos, em que a superfície dos cortes atinge temperaturas mais elevadas antes do interior, causando a desnaturação das proteínas superficiais, tornando-as insolúveis e resultando na formação de uma camada que contribui para a redução de perdas de água por gotejo (drip) e evaporação (ROSA, 2003).

A análise de variância revelou influência dos métodos de cocção $(\mathrm{P}<0,01)$ e da linhagem $(\mathrm{P}<0,05)$ sobre a umidade do peito de frangos (Tabela 2). A linhagem Cobb apresentou o maior valor médio de umidade $(66,11 \%)$, enquanto as linhagens Carijó e Super pesadão foram semelhantes, com valores de $65,12 \%$ e $64,76 \%$, respectivamente. As médias de umidade para os peitos crus encontradas no presente trabalho foram de $74,67 \%$ para a linhagem Carijó, $73,76 \%$ para a Super pesadão e 73,82\% para Cobb. Trabalhando com as mesmas linhagens, Souza (2004) observou valores mais elevados $(\mathrm{P}<0,01)$ de umidade nas linhagem Cobb $(75,57 \%)$ e Carijó $(75,23 \%)$ do que a Super pesadão $(75,06 \%)$.

O cozimento induziu a diminuição da umidade. As amostras cruas apresentaram valores mais elevados de umidade do que as amostras submetidas aos métodos de cocção, dos quais os menores valores foram observados em peitos assados em microondas. Comportamento semelhante foi encontrado por Gokoglu et al. (2004), em trutas arco-íris submetidas aos métodos frito em óleo, cozido em água, assado em forno convencional, grelhado e assado em microondas que observaram valores mais baixos de umidade nos filés assados em microondas.

TABELA 1 - Valores médios (\%) de perda de peso por cocção (PPC) em peitos de frangos submetidos a diferentes métodos de cocção.

\begin{tabular}{ccccc}
\hline Métodos de cocção & \multicolumn{3}{c}{ Linhagens } & Médias \\
\cline { 2 - 4 } & Carijó & $\begin{array}{c}\text { Super } \\
\text { pesadão }\end{array}$ & Cobb \\
\hline Cozido em água & 21,97 & 20,23 & 17,78 & $19,99^{\mathrm{c}}$ \\
Frito em óleo & 24,97 & 22,67 & 21,29 & $22,98^{\mathrm{c}}$ \\
Forno & 33,65 & 26,53 & 31,60 & $30,59^{\mathrm{b}}$ \\
Microondas & 55,27 & 52,82 & 48,97 & $52,35^{\mathrm{a}}$ \\
\hline Médias & $33,96^{\mathrm{A}}$ & $30,56^{\mathrm{B}}$ & $29,91^{\mathrm{B}}$ & \\
\hline
\end{tabular}

Médias seguidas da mesma letra minúscula na coluna e maiúscula na linha são estatisticamente iguais entre si pelo teste de Scott-Knott ao nível de $5 \%$ de probabilidade $(\mathrm{P}<0,05)$.

Ciênc. agrotec., Lavras, v. 31, n. 1, p. 164-170, jan./fev., 2007 
TABELA 2 - Valores médios de componentes da composição centesimal, do peito de frangos submetidos a diferentes métodos de cocção.

\begin{tabular}{|c|c|c|c|c|c|}
\hline & \multirow[b]{2}{*}{ Métodos de cocção } & \multicolumn{3}{|c|}{ Linhagens } & \multirow[t]{2}{*}{ Médias } \\
\hline & & Carijó & $\begin{array}{c}\text { Super } \\
\text { pesadão }\end{array}$ & Cobb & \\
\hline \multirow{6}{*}{ Umidade } & Cru & 74,67 & 73,76 & 73,82 & $74,08^{\mathrm{a}}$ \\
\hline & Cozido em água & 69,98 & 68,93 & 69,53 & $69,48^{\mathrm{b}}$ \\
\hline & Frito em óleo & 62,43 & 62,99 & 65,76 & $63,73^{\mathrm{c}}$ \\
\hline & Forno & 62,79 & 61,72 & 65,03 & $63,18^{\mathrm{c}}$ \\
\hline & Microondas & 55,74 & 56,40 & 56,41 & $56,18^{\mathrm{d}}$ \\
\hline & Médias & $65,12^{\mathrm{B}}$ & $64,76^{\mathrm{B}}$ & $66,11^{\mathrm{A}}$ & \\
\hline \multirow{6}{*}{ Proteína } & $\mathrm{Cru}$ & 23,23 & 23,62 & 23,76 & $23,54^{\mathrm{e}}$ \\
\hline & Cozido em água & 27,87 & 29,47 & 28,76 & $28,70^{\mathrm{d}}$ \\
\hline & Frito em óleo & 32,42 & 32,73 & 31,00 & $32,05^{\mathrm{c}}$ \\
\hline & Forno & 34,10 & 35,74 & 32,39 & $34,07^{\mathrm{b}}$ \\
\hline & Microondas & 41,08 & 39,82 & 39,76 & $40,22^{\mathrm{a}}$ \\
\hline & Médias & 31,74 & 32,27 & 31,13 & \\
\hline \multirow{6}{*}{ Gordura } & Cru & $0,92^{\mathrm{cA}}$ & $1,00^{\mathrm{cA}}$ & $1,29^{\mathrm{cA}}$ & 1,07 \\
\hline & Cozido em água & $1,08^{\mathrm{cA}}$ & $1,30^{\mathrm{cA}}$ & $1,17^{\mathrm{cA}}$ & 1,18 \\
\hline & Frito em óleo & $2,53^{\mathrm{aB}}$ & $3,23^{\mathrm{aA}}$ & $1,94^{\mathrm{aC}}$ & 2,56 \\
\hline & Forno & $1,54^{\mathrm{bA}}$ & $1,43^{\mathrm{cA}}$ & $1,68^{\mathrm{bA}}$ & 1,55 \\
\hline & Microondas & $1,45^{\mathrm{bB}}$ & $2,29^{\mathrm{bA}}$ & $1,86^{\mathrm{aB}}$ & 1,87 \\
\hline & Médias & 1,50 & 1,85 & 1,59 & \\
\hline \multirow{6}{*}{ Cinzas } & $\mathrm{Cru}$ & 0,92 & 1,04 & 0,87 & $0,94^{\mathrm{c}}$ \\
\hline & Cozido em água & 1,00 & 0,67 & 0,92 & $0,86^{\mathrm{c}}$ \\
\hline & Frito em óleo & 1,20 & 1,19 & 1,19 & $1,19^{b}$ \\
\hline & Forno & 1,28 & 1,09 & 1,18 & $1,18^{b}$ \\
\hline & Microondas & 1,64 & 1,87 & 1,41 & $1,64^{\mathrm{a}}$ \\
\hline & Médias & 1,21 & 1,17 & 1,11 & \\
\hline
\end{tabular}

Médias seguidas da mesma letra minúscula na coluna e maiúscula na linha são estatisticamente iguais entre si pelo teste de Scott-Knott ao nível de $5 \%$ de probabilidade $(\mathrm{P}<0,05)$.

As médias de umidade, lipídeos totais, proteína e cinzas do peito de frangos, submetidos a diferentes métodos de cocção, estão apresentadas na Tabela 2.

Rosa (2003) encontrou, em peito de frangos submetidos a métodos de cocção semelhantes, menores valores de umidade em peitos assados em microondas e fritos em óleo. Entretanto, Gall et al. (1983), avaliando os métodos assado em forno convencional, grelhado, assado em microondas e frito em óleo e seus efeitos em filés de peixes marinhos, relataram menores valores de umidade em filés fritos em óleo e nos demais métodos, as médias foram semelhantes.

Os percentuais de proteína e de cinzas foram influenciados pelo método de cocção $(\mathrm{P}<0,01)$. O menor valor de proteína foi encontrado nos cortes crus $(23,54 \%)$. Os cortes de peito submetidos ao método assado em microondas apresentaram valor médio de 40,22\%. Esses resultados estão de acordo com aqueles relatados por: Rosa (2003), em peitos de frangos assados em microondas; Gokoglu et al. (2004) em filés de truta; Gall et al. (1983) em filés de peixes marinhos (garoupa, caranha vermelha, pampo da Flórida e cavalinha); e por Puwastien et al. (1999) em filés de tilápia, bagre africano e catfish. Os autores atribuíram tal comportamento à maior perda de água proporcionada por esse tratamento, favorecendo a concentração de proteínas.

O maior percentual de cinzas foi encontrado no método assado em microondas $(1,6 \%)$, seguido pelo método assado em forno convencional $(1,18 \%)$ e frito em óleo $(1,19 \%)$, que foram semelhantes. O método cozido em água apresentou valor médio de cinzas de 0,86\%, semelhante aos filés crus $(0,94 \%)$. Ferreira (2005), avaliando 
a composição centesimal (com base na matéria seca) de filés de tilápia, observou maiores teores de cinzas nos filés assados em microondas. Entretanto, Rosa (2003) observou em peitos de frangos, valores de cinzas mais elevados nos métodos assado em microondas, grelhado e frito em óleo; e, Gokoglu et al. (2004), em filés de truta observaram valores mais elevados no método frito em óleo.

A literatura não explica com clareza a relação entre cinzas, método de cocção e os outros constituintes dos alimentos. Gall et al. (1983), trabalhando com filés de peixes de diferentes espécies, relataram que as perdas de umidade devido ao cozimento resultaram na concentração do teor de cinzas.

Para os valores médios de gordura (Tabela 2), houve interação entre os fatores método de cozimento e linhagem $(\mathrm{P}<0,01)$. Os peitos crus e os submetidos ao método assado em forno convencional e cozidos em água foram semelhantes em todas as linhagens estudadas. No método assado em microondas, a linhagem Super pesadão apresentou valores mais elevados $(2,29 \%)$ do que as linhagens Carijó $(1,45 \%)$ e Cobb $(1,86 \%)$. Os percentuais de gordura aumentaram quando comparados peitos crus com peitos assados em microondas de 57,60\%, $129 \%$ e 44,18\% nas linhagens Carijó, Super pesadão e Cobb, respectivamente, quando comparados aos peitos crus. O método frito em óleo apresentou diferenças em todas as linhagens, com aumento nos percentuais de gordura de 175\% para a linhagem Carijó; $223 \%$ para a Super pesadão e $50,38 \%$ para a linhagem Cobb, quando comparados aos peitos crus, fato que pode ser explicado pela absorção de lipídeos do meio de cocção.

Ferreira (2005), avaliando filés de tilápia submetidos à cocção, verificou que os métodos frito em óleo, assados em microondas e em forno elétrico, apresentaram médias mais elevadas de gordura (na base seca), enquanto os filés cozidos em água foram semelhantes aos crus. Houve aumento no teor de gordura de $65 \%$ nos filés assados em microondas e de $193 \%$ nos fritos em óleo. Rosa (2003), estudando métodos de cocção semelhantes aos do presente trabalho, em peito e coxa de frangos, relatou valores mais elevados no método frito em óleo.

Nas linhagens Super pesadão e Cobb, o maior percentual de gordura foi encontrado no método frito em óleo (3,23\% e 1,94\%, respectivamente), seguido pelo método assado em microondas (2,29\% e 1,86\%, respectivamente). Os cortes crus, assados em forno convencional e cozidos em água não apresentaram diferenças na linhagem Super pesadão, apresentando valores de 1,00\%; 1,43\% e 1,30\%, respectivamente. $\mathrm{Na}$ linhagem $\mathrm{Cobb}$, os peitos cozidos em água foram semelhantes aos crus.

Para a linhagem Carijó, o maior valor de gordura foi encontrado nos peitos fritos em óleo, com percentual de $2,53 \%$, seguido pelos métodos assado em forno convencional (1,54\%), assado em microondas $(1,45 \%) \mathrm{e}$ cozidos em água $(1,08 \%)$. Os cortes crus apresentaram o menor valor de gordura $(0,92 \%)$.

De modo geral, os percentuais de gordura dos cortes crus foram menores que nos cortes cozidos, e a maior diferença ocorreu nos cortes submetidos ao método frito em óleo, provavelmente em decorrência da absorção da gordura do meio de cocção. Além disso, no presente trabalho foi observado que os cortes que apresentaram maior conteúdo lipídico inicial (cru) absorveram menor quantidade de gordura do meio, semelhante aos resultados reportados por Gall et al. (1983) e Mai et al. (1978) em filés de peixes de várias espécies. Rosa (2003) também observou menor aumento no teor lipídico pós-cozimento nos cortes de coxa fritos em óleo (quando comparados aos de peito), que apresentavam maior valor de gordura inicial.

Os teores de colesterol do peito de frangos das diferentes linhagens estão representados na Tabela 3.

TABELA 3 - Valores médios de colesterol $(\mathrm{mg} / 100 \mathrm{~g})$ no peito de frangos submetidos a diferentes métodos de cocção.

\begin{tabular}{ccccc}
\hline Métodos de cocção & \multicolumn{3}{c}{ Linhagens } & \multirow{2}{*}{ Médias } \\
\cline { 2 - 4 } & Carijó & Super pesadão & Cobb & \\
\hline Cru & 39,44 & 38,08 & 45,96 & $41,16^{\mathrm{c}}$ \\
Cozido em água & 53,36 & 52,24 & 58,01 & $54,54^{\mathrm{b}}$ \\
Frito em óleo & 54,46 & 49,14 & 51,12 & $51,58^{\mathrm{b}}$ \\
Forno & 57,03 & 57,84 & 56,93 & $57,27^{\mathrm{b}}$ \\
Microondas & 60,10 & 64,00 & 67,56 & $63,89^{\mathrm{a}}$ \\
\hline Médias & 52,88 & 52,26 & 55,92 & \\
\hline
\end{tabular}

Médias seguidas da mesma letra minúscula na coluna e maiúscula na linha são estatisticamente iguais entre si pelo teste de Scott-Knott ao nível de $5 \%$ de probabilidade $(\mathrm{P}<0,05)$.

Ciênc. agrotec., Lavras, v. 31, n. 1, p. 164-170, jan./fev., 2007 
Os dados submetidos à análise de variância demonstraram que os teores de colesterol foram influenciados $(\mathrm{P}<0,01)$ pelo método de cocção, de forma que todos os métodos aumentaram significativamente os valores de colesterol do peito de frangos, devido à perda de água, levando à concentração de nutrientes. A média mais elevada foi observada no método assado em microondas $(63,89 \mathrm{mg} / 100 \mathrm{~g})$ e não houve diferença entre os métodos forno convencional $(57,27 \mathrm{mg} / 100 \mathrm{~g})$; cozido em óleo (51,58 $\mathrm{mg} / 100 \mathrm{~g})$ e cozido em água $(54,54 \mathrm{mg} / 100 \mathrm{~g}) . \mathrm{O}$ menor valor médio foi observado nos cortes crus $(41,16 \mathrm{mg} / 100 \mathrm{~g})$.

Os valores do presente trabalho estão de acordo com aqueles reportados por Ferreira (2005) em filés de tilápia, que apresentaram médias mais elevadas em filés assados em microondas. Rosa (2003) verificou aumento significativo de colesterol nos cortes cozidos em relação aos crus, porém não houve diferenças entre os métodos de cocção. As médias mais elevadas foram observadas em peito frito em óleo $(116,93 \mathrm{mg} / 100 \mathrm{~g})$ e em coxa grelhada $(128,33 \mathrm{mg} / 100 \mathrm{~g})$. De acordo com isso, Bragagnolo \& Rodriguez-Amaya (1992) também observaram aumento no colesterol em carnes vermelhas e em carnes brancas (frangos) assados em forno convencional.

Vários autores relatam que ocorre a concentração de nutrientes durante o cozimento, em decorrência da perda de água para o meio de cocção, elevando o colesterol (BADIANI et al., 2002; BRAGAGNOLO \& RODRIGUEZ-AMAYA, 1992; FERREIRA, 2005; ROSA, 2003). Entretanto, alguns estudos relatam a diminuição do colesterol total após o cozimento, tais como: Mai et al. (1978) que observaram redução na concentração de colesterol em filés de pescado grelhados, assados em forno convencional e fritos; e, Candela et al. (1996), que verificaram redução entre 15 e $22 \%$ no colesterol em três tipos de pescado. Os autores associaram a perda de colesterol à sua diluição no óleo de fritura.

\section{CONCLUSÕES}

A cocção determina perdas na umidade e, considerando os métodos estudados, peitos de frango assados em microondas apresentam as perdas mais elevadas e, em conseqüência disso, esse método determina as modificações mais severas com relação à composição química do peito cru; e, o cozimento em água é a forma de cocção que menos altera a composição centesimal de peitos de frangos.

\section{AGRADECIMENTOS}

Os autores agradecem ao $\mathrm{CNPq}$ (Conselho Nacional de Desenvolvimento Científico e Tecnológico) e à CAPES, pela concessão de bolsas de mestrado, doutorado e produtividade.

\section{REFERÊNCIAS BIBLIOGRÁFICAS}

ASSOCIATION OF OFFICIAL ANALYTICAL CHEMISTS. Official methods of analysis of the Association of Official Analytical Chemists. 15. ed. Arlington, 1990.

BADIANI, A.; STIPA, S.; BITOSSI, F.; GATTA, P. P.; VIGNOLA, G.; CHIZZOLINI, R. Lipid composition, retention and oxidation in fresh and completely trimmed beef muscles as affected by commom culinary practices. Meat Science, Oxford, v. 60, n. 2, p. 169-186, Feb. 2002.

BRAGAGNOLO, N.; RODRIGUEZ-AMAYA, D. B. Teores de colesterol em carnes de frango. Revista de Farmácia e Bioquímica da Universidade de São Paulo, São Paulo, v. 28, n. 2, p. 122-131, jul./dez. 1992.

BRAGAGNOLO, N.; RODRIGUEZ-AMAYA, D. B. Teores de colesterol em carnes bovina e suína e efeito do cozimento. Ciência e Tecnologia dos Alimentos, Campinas, v. 15, n. 1, p. 11-17, 1995.

CANDELA, M.; ASTIASARAN, I.; BELLO, J. Effect of frying on the fatty acid profile of some meat dishes. Journal of Food Composition and Analysis, San Diego, v. 9, p. 277-282, 1996.

FERREIRA, D. F. Analises estatísticas por meio do Sisvar para o Windows versão 4.0. In: REUNIÃO ANUAL DA REGIÃO BRASILEIRA DA SOCIEDADE INTERNACIONAL DE BIOMETRIA, 45., 2000, São Carlos. Anais... São Carlos: UFSCar, 2000. p. 255-258.

FERREIRA, M. W. Composição química e perfil lipídico do filé de Tilápia do Nilo (Oreochromis niloticus Linnaeus 1757) cru e submetido a diferentes métodos de cocção. 2005. 80 p. Dissertação (Mestrado em Ciência dos Alimentos) - Universidade Federal de Lavras, Lavras, 2005.

FOLCH, J.; LESS, M.; STANLEY, S. A simple method for the isolation and purification of total lipids from animal tissues. Journal of Biological Chemistry, Baltimore, v. 226, n. 1, p. 497-509, May 1957.

GALL, K. L.; OTWELL, W. S.; KOBUGUER, J. A.; APPLEDORF, $\mathrm{H}$. Effects of four cooking methods on the proximate, mineral and fatty acid composition of fish fillets. Journal of Food Science, Chicago, v. 48, n. 4, p. 1068-1074, July/Aug. 1983. 
GARCÍA-ARIAS, M. T.; ÁLVAREZ PONTES, E.; GARCÍALINARES, M. C.; GARCÍA-FERNÁNDEZ, M. C.; SÁNCHEZ-MUNIZ, F. J. Cooking-freezing-reheating (CFR) of sardine (Sardina pilchardus) fillets: efect of different cooking and reheating procedures on the proximate and fatty acid compositions. Food Chemistry, Oxford, v. 83, n. 3, p. 349-356, Nov. 2003.

GOKOGLU, N.; YERLIKAYA, P.; CENGIZ, E. Effects of cooking methods on the proximate composition and mineral contents of rainbow trout (Oncorhynchus mykiss). Food Chemistry, Oxford, v. 84, n. 1, p. 19-22, Jan. 2004.

MAI, J.; SHIMP, J.; WEIHRAUC, J.; KINSELLA, J. E. Lipids of fish fillets: changes following cooking by different methods. Journal of Food Science, Chicago, v. 43, n. 6, p. 1669-1674, Nov./Dec. 1978.

PUWASTIEN, P.; JUDPRASONG, K.; KETTWAN, E.; VASANACHITT, K.; NAKNGAMANONG, Y.; BHATTACHATTACHARJEE, L. Proximate composition of raw and cooked thai freshwater and marine fish. Journal of Food Composition and Analysis, San Diego, v. 12, n. 1, p. 9-16, Mar. 1999.
ROSA, F. C. Composição química e métodos de cocção de carcaça de frangos de corte alimentados com rações suplementadas com ômega-3. 2003. 131 p. Tese (Doutorado em Ciência dos Alimentos) - Universidade Federal de Lavras, Lavras, 2003.

SIMOPOULOS, A. P. Summary of the nato advanced research workshop on dietary w-3 and w-6 fatty acids: biological effects and nutritional essentiality. American Institute of Nutrition, Philadelphia, v. 22, p. 521-526, 1991.

SOUZA, X. R. Características de carcaça, qualidade de carne e composição lipídica de frangos de corte criados em sistemas de produção caipira e convencional. 2004. 329 p. Tese (Doutorado em Ciência dos Alimentos) Universidade Federal de Lavras, Lavras, 2004.

STEINER-ASIEDU, M.; JULSHAMN, K.; LIE, O. Effects of local processing methods (cooking, frying and smoking) on three fish species from Ghana: part I: proximate composition, fatty acids, minerals, trace elements and vitamins. Food Chemistry, Oxford, v. 40, n. 3, p. 309-321, 1991. 